\title{
REVISTAMARACANAN
}

\section{De grande aldeia a metrópole: reforma urbana, fotografia e discurso do progresso em Buenos Aires (1880-1885)}

\section{From a large village to a metropolis: urban reform, photography and the discourse about progress in Buenos Aires (1880-1885)}

\author{
Viviane da Silva Araujo \\ Universidade Federal da Integração Latino-Americana \\ viviane.araujo@unila.edu.br
}

\begin{abstract}
Resumo: As duas últimas décadas do século XIX em Buenos Aires foram marcadas por uma série de reformas urbanas. Estas objetivavam erguer, material e idealmente, uma capital moderna, salubre e cosmopolita, capaz de identificar-se ao "mundo civilizado". Este artigo analisa o álbum fotográfico encomendado, em 1885, pelo então prefeito de Buenos Aires, Torcuato de Alvear, partindo do pressuposto de que ao mesmo tempo que documentava as reformas urbanas, o álbum era parte das estratégicas de construção simbólica das reformas então empreendidas. Por meio da análise dos temas abordados no álbum e da composição visual das fotografias, pretende-se relacionar os conteúdos das imagens à promoção dos discursos de progresso, salubridade e modernidade urbana.
\end{abstract}

Palavras-chave: Fotografia; Reforma urbana; Salubridade; Progresso.

\begin{abstract}
In the last two decades of the nineteenth century, Buenos Aires experienced a series of urban reforms. These aimed at lifting, concretely and ideally, a wholesome, cosmopolitan, modern capital which could identify itself with the "civilized world". This article analyzes the photo album commissioned in 1885 by the mayor of Buenos Aires, Torcuato de Alvear, starting from the assumption that, along with the documentation of urban reform, the album was also part of the symbolic construction of those reforms. Through analysis of the themes on the album and the visual composition of its photographs, this article intends to relate the images' content to the discourses being promoted, about progress, healthiness and urban modernity.
\end{abstract}

Keywords: Photography; Urban reform; Healthiness; Progress.

Artigo recebido para publicação em: Outubro de 2015

Artigo aprovado para publicação em: Dezembro de 2015 


\title{
Introdução
}

\begin{abstract}
Para se ter uma ideia cabal do progresso da metrópole, nada melhor do que observar uma fotografia antiga. As estatísticas, os livros, as informações de testemunhas verídicas: nada tem o valor convincente da fotografia. Convence em primeiro lugar aos olhos, que são os órgãos quase exclusivos para se interpretar Buenos Aires. Buenos Aires se interpreta com os olhos porque foi construída para ser vista. Daí o poder de fascinação que exerce: olhando a cidade se inibe a faculdade do raciocínio e assim a negamos ou afirmamos em estado hipnótico. ${ }^{* 1}$
\end{abstract}

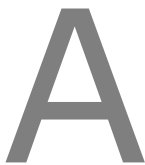

recomendação de Ezequiel Martínez Estrada àqueles que desejassem obter uma noção exata dos progressos de Buenos Aires até aquele momento era que examinassem uma fotografia antiga, pois nenhum outro testemunho ou investigação sobre o passado poderia ser tão convincente para os observadores do presente. 0 presente, a partir do qual enunciava tal recomendação, era o final da década de 1930, quando o autor escreveu os ensaios que formaram o livro La cabeza de Goliat: microscopía de Buenos Aires, publicado em 1940; e o passado ao qual se referia era o último quartel do século XIX, um período de grande desenvolvimento da atividade fotográfica, bem como de intensas transformações urbanas, quando a cidade se tornou algo construído para "ser visto". A partir dessa afirmativa, Estrada defendia que desde 1880, quando a cidade definitivamente se tornou a capital da República Argentina, o desenvolvimento de Buenos Aires não era apenas passível de ser observado, mas a partir de então a construção da imagem do progresso passava a ser um objetivo central das transformações ali engendradas.

O período de paz interna, marcado por uma modernização conservadora que se estende entre as décadas de 1880 e 1910, favoreceu o crescimento populacional, especialmente de Buenos Aires que, de 1869 a 1895, passou de 187.346 para 663.854 habitantes e, em 1914, chegaria a 1.575.814, sendo mais da metade constituída por estrangeiros. ${ }^{2}$ Diante desse crescimento, defendia-se a necessidade de modernizar sua estrutura urbana, questionando cada vez mais a antiga configuração herdada do período colonial: a "grande aldeia", ${ }^{3}$ erguida à margem do Rio da Prata, com suas ruas estreitas dispostas em quadrículas sobre um pequeno pedaço da imensidão pampeana deveria ser substituída por uma configuração urbana moderna, racional e, ao mesmo tempo, suntuosa, salubre, capitalista, capaz de corresponder às novas necessidades materiais e às novas demandas culturais.

Desse modo, para além de questões administrativas, a federalização de Buenos Aires, em 1880, marcaria o início de uma série de reformas urbanas modernizadoras, cujos esforços primordiais se identificam sobretudo nos projetos urbanísticos de Torcuato de Alvear. Durante

\footnotetext{
* Todas as traduções do original em espanhol são livres e de minha autoria.

${ }^{1}$ ESTRADA, Ezequiel Martínez. La cabeza de Goliat. Microscopía de Buenos Aires. Buenos Aires: Capital Intelectual, 2009. p. 43.

2 Cf. ROMERO, José Luis; ROMERO, Luis Alberto (Orgs.). Buenos Aires: historia de cuatro siglos. Tomo II. Buenos Aires: Editorial Abril, 1983. p. 275.

3 A expressão "grande aldeia" foi cunhada por Lucio Vicente López em 1884, quando publicou o romance histórico La gran aldea, cuja trama se desenvolve na Buenos Aires das décadas posteriores à queda de Rosas (1852). Desde então, "grande aldeia" tem sido utilizada como uma expressão sintética para caracterizar a Buenos Aires anterior à modernização empreendida a partir de 1880.
} 
o período em que presidiu a Comisión Municipal (1880-1883) e, depois, quando se tornou o primeiro prefeito da municipalidade de Buenos Aires, cargo que exerceu por dois mandatos consecutivos (1883-85/1885-87), foram realizadas as seguintes medidas: alargamento e pavimentação de diversas ruas; construção ou recuperação de praças e passeios; reforma de cemitérios; regulamentação de matadouros e de mercados de abastecimento; fundação da Assistência Pública; construção e reforma de hospitais; implantação de vacinação obrigatória contra varíola; entre outras iniciativas que envolviam a melhoria das condições de salubridade e o embelezamento da cidade. Somam-se a essas medidas, duas obras que reforçariam o apelo simbólico de um marco histórico não apenas da cidade de Buenos Aires, mas da nacionalidade argentina: a unificação da Plaza de la Victoria e da Plaza 25 de Mayo, com a demolição da Recova Vieja, em 1883, formando assim a atual Plaza de Mayo; além do projeto de construção de um moderno bulevar leste-oeste que ligaria a Plaza de Mayo e a Plaza Lorea (hoje, Plaza del Congreso): a futura Avenida de Mayo, inaugurada em 1894.

Essas medidas se sustentavam sobre uma ideia de inserção na modernidade fundamentada em grande medida no desenvolvimento dos espaços urbanos, por reunirem a maior parte das atividades econômicas, políticas e culturais de seus países, além de uma população cada vez mais numerosa. Tal noção de modernidade se baseava, ao menos para as elites políticas que geriram esse processo, para intelectuais de inclinação otimista e setores médios entusiastas, numa crença nas virtudes pedagógicas do espaço urbano. Segundo essa perspectiva, uma cidade bela, limpa e grandiosa conduziria a sociedade à grandeza; do mesmo modo que uma cidade pobre, suja e acanhada levaria aquela sociedade a um destino igualmente mesquinho. Tendo como referência noções de planejamento urbano e ideais de civilidade e progresso desenvolvidos na Europa, embora sempre refeitos à luz dos anseios e das possibilidades locais, a Buenos Aires do último quartel do século XIX viveu um momentochave do seu processo de metropolização.

Ao se referir, por exemplo, às reformas urbanas empreendidas entre as décadas de 1850 e 1870, em Paris, por Georges Eugène Haussmann, Walter Benjamin observou que o desejo de dirigir a modernidade através da reforma urbana partiu do pressuposto de que a retificação das ruas, o saneamento e a iluminação pública eram mais do que obras de construção civil, realizadas com pás, enxadas e alavancas. Em relação à ideia de condução da modernidade fundamentada na proposta de reformar a cidade, o arrasamento do que anteriormente estava estabelecido parecia se apresentar como condição necessária para a construção do novo. As grandes cidades se fariam na medida em que se desenvolvessem os meios de destruição que promoveriam a extinção do que não mais convinha num espaço urbano modernizado. Desse modo, a reforma urbana representaria uma espécie de atalho na direção do porvir e, ao passo que derrubava os vestígios do passado, construía poderosas imagens do futuro.

A cidade de Paris ingressou neste século sob a forma que the foi dada por Haussmann. Ele realizou sua transformação da imagem da cidade com os meios mais modestos que se possa pensar: pás, enxadas, alavancas e 
coisas semelhantes. Que grau de destruição já não provocaram esses instrumentos limitados! E como cresceram, desde então, com as grandes cidades, os meios de arrasá-las! Que imagens do porvir já não evocam! ${ }^{4}$

Ao mesmo tempo que reconhecia o poder transformador desses "modestos" instrumentos empregados nas obras de Haussmann, Benjamin caracterizou tais obras como transformações da "imagem" da cidade. Contudo, com isso não quis dizer que a única coisa que efetivamente se transformava era o universo tangível da urbe, fossem os quarteirões demolidos, ou os bulevares, as praças e os edifícios construídos em seu lugar. Transformar a imagem da cidade seria, na verdade, um meio poderoso de ao mesmo tempo transformar o modo como os habitantes a imaginavam e sentiam.

No início da década de [18]50, a população parisiense começou a aceitar a ideia de uma grande e inevitável expurgação da imagem urbana. Podese supor que, em seu período de incubação, essa limpeza fosse capaz de agir sobre uma fantasia significativa com tanta força, se não mais, quanto o espetáculo dos próprios trabalhos urbanísticos. ${ }^{5}$

A produção de um imaginário moderno para a cidade que vivia tais reformas se dava não apenas pelas reformas em si, como também pelas representações culturais que davam sentido às transformações, entre as quais, no presente artigo, destaca-se a fotografia. Para analisar o papel desempenhado pela fotografia como instrumento de documentação, publicização e legitimação das reformas urbanas - ou, para retomar os termos de Ezequiel Martínez Estrada, como um meio de visualizar de modo cabal o nascimento de uma metrópole construída para ser vista -, é importante considerar que o intervalo de tempo, no qual se desenvolveram obras que modificaram radicalmente a aparência ou a função dos antigos espaços, era relativamente curto e efêmero. Ainda que uma obra durasse alguns anos, tratava-se sempre de um tempo provisório, um período reconhecido como uma transição no caminho entre o passado e o futuro. Por isso, fixar esse momento transitório, eternizá-lo através da fotografia, funcionava como uma maneira de inscrevê-lo na história da cidade, como um período, embora curto, de grande relevância simbólica.

\section{O álbum das melhorias de Buenos Aires}

O momento era propício para a exibição de suas realizações quando, em julho de 1885, o recentemente reeleito prefeito de Buenos Aires, Torcuato de Alvear, encomendou a Emilio Halitzky - fotógrafo de origem húngara radicado na Argentina entre 1866 e $1890^{6}$ - um álbum fotográfico que expusesse as principais realizações de seus mandatos como presidente da Comisión Municipal, entre 1880 e 1883, e como prefeito da Capital Federal, entre 1883 e

\footnotetext{
${ }^{4}$ BENJAMIN, Walter. Charles Baudelaire: um lírico no auge do capitalismo. In: Obras Escolhidas, v. 3. São Paulo: Brasiliense, 1989. p. 84.

${ }^{5}$ Id., p. 85

6 Cf. MÉNDEZ, Patricia; RADOVANOVIC, Elisa. Las imágenes del progreso: Torcuato de Alvear y Emilio Halitzky. Memoria del 70 Congreso de Historia de la Fotografía en Argentina. Buenos Aires: Archivo General de la Nación / Sociedad Iberoamericana de Historia de la Fotografía, 2003. p. 153.
} 
1885. As fotografias que comporiam o álbum intitulado Mejoras de la capital de la República Argentina llevado a cabo durante la administración del intendente Torcuato de Alvear, 1880 1885 deveriam apresentar a nova configuração dos espaços urbanos reformados e os empreendimentos relativos à saúde pública, de modo que estes fossem identificados ao ideário de progresso almejado para a cidade. Desse modo, a produção do álbum pode ser tomada como parte das estratégias políticas e culturais de construção de uma imagem positiva para essas intervenções urbanas.

Conforme evidenciam as felicitações prestadas ao prefeito pelo semanário El Mosquito, em 24 de maio de 1885, por ocasião de sua reeleição, ao mesmo tempo que se exaltavam as transformações já realizadas, admitia-se que havia ainda muito a ser feito. Segundo o periódico, os passos dados até então demonstravam que valia a pena manter o prefeito no cargo por mais dois anos. Contudo, ao mesmo tempo que parabenizava sua obra, sugeria o direcionamento dos próximos empreendimentos, a fim de completá-los, para a parte sul da cidade:

O que era Buenos há seis anos atrás? Era então um lamaçal, um inferno para os pedestres e os veículos, uma provisão para pedicuros e fabricantes de carruagens.

Ainda hoje deixa a desejar, certamente, mas "Paris não se faz em um dia" e o que tem feito o Sr. Prefeito até este momento já é enorme.

$[\ldots]$

O Sr. de Alvear deixará marcas inesquecíveis de sua passagem pela prefeitura da Capital. Graças ao seu espírito empreendedor, sua perseverança e dedicação ao trabalho, vemos de um dia para o outro se transformar a fisionomia de bairros inteiros. Teria sido uma desgraça para a Capital a não reeleição de tão eminente cidadão como Prefeito, pois ainda Ihe resta completar sua obra e empregar seus dotes especiais para o bem do município, especialmente em sua parte sul. ${ }^{7}$ (Grifo meu)

De acordo com Patricia Méndez e Elisa Radovanovic, ${ }^{8}$ é possível que Alvear tenha encomendado a realização do álbum a Halitzky justamente para divulgar as realizações de seu governo, sobretudo em prol da saúde pública, em diferentes regiões da cidade, diante das críticas que vinha recebendo na imprensa. Segundo tais críticas, Alvear daria demasiada atenção às obras de ornamentação, deixando de lado questões mais relevantes ligadas à pavimentação e à resolução de problemas relativos à salubridade e qualidade de vida da população, especialmente na região sul de Buenos Aires e nas áreas baixas constantemente sujeitas a inundações. Os bairros de San Telmo, Barracas e La Boca, vitimados no início da década anterior por uma grave epidemia de febre amarela, tornavam-se áreas de grande concentração de moradias coletivas e insalubres, frequentemente construídas precariamente com materiais como madeira e chapas metálicas, que ficaram conhecidas como "conventillos", habitadas por muitos imigrantes recém-chegados à cidade. Por vezes, chegou-se a acusar o prefeito de priorizar a realização de obras de embelezamento, arborização e drenagem em

\footnotetext{
7 Don Torcuato de Alvear. El mosquito, 24/05/1885. Texto de autoria não identificada.

8 MÉNDEZ, Patricia; RADOVANOVIC, Elisa. Op. cit., 2003.
} 
locais próximos à sua própria residência, especialmente nos bairros da Recoleta e de Palermo, que eram cada vez mais procurados pelas classes altas portenhas.

Ainda que não buscasse responder diretamente a tais acusações, Alvear procurou, com a realização do álbum, dar visibilidade aos seus feitos, dispondo-os de modo a apresentar uma série de transformações, e não somente de embelezamento nem direcionadas apenas para o centro e a zona norte, mas exibindo também reformas realizadas nas áreas ao sul e a oeste do núcleo urbano central. Nesse momento, a área correspondente à Capital Federal era de um pouco mais de 4 mil hectares, embora a região efetivamente ocupada fosse ainda menor. A ampliação dos seus limites territoriais se deu em 1887, a partir da incorporação de 14 mil hectares, cedidos pela província de Buenos Aires ao município, área que incluía os povoados de Flores e Belgrano, além de uma ampla extensão territorial a oeste da ocupação original, ainda desabitada. ${ }^{9}$

Ao acompanhar o percurso das páginas do álbum, podemos tentar compreender o seu argumento, embora exista a possibilidade de percorrer as páginas de um álbum fotográfico sem necessariamente obedecer à ordem sugerida por sua sequência. No caso do álbum das melhorias de Buenos Aires, o caminho percorrido foi, na verdade, mais temático do que geográfico. Inicia-se com três imagens da Plaza de la Victoria, sendo uma a reprodução do projeto assinado pelo próprio Alvear, em 1883, e duas fotografias da praça; em seguida, percorre outros parques e passeios que foram construídos ou remodelados, em nove tomadas fotográficas; depois, apresenta hospitais e asilos, tema que ocupou a maior parte do álbum, com doze fotos; a seguir, apresenta três fotografias de ruas que receberam obras de terraplanagem e pavimentação; três fotografias do recém-reformado cemitério da Recoleta; e, por último, duas reproduções de projetos de um monumento para substituir a Pirâmide de Mayo, a ser colocado no centro da praça homônima depois de reformada, proposta que foi rechaçada e nunca saiu do papel.

Ao incluir reproduções de projetos arquitetônicos, o álbum relacionava planejamento e execução, colocando em evidência o caráter prospectivo da cidade que surgia a partir das reformas. O nome do personagem principal desse empreendimento, já explicitado no título do álbum, é ratificado ao iniciá-lo com o projeto de reformulação da Plaza de la Victoria produzido por Alvear. O projeto (Figura 1) previa uma praça nova, formada pela união entre a Plaza de la Victoria e a Plaza 25 de Mayo, a partir da demolição da Recova Vieja; o novo monumento comemorativo à Revolução de 1810, no centro; a abertura do bulevar de 30 varas de largura, a Avenida de Mayo; a Casa de Governo já unificada ao prédio dos Correios e alguns espaços dedicados à construção de edifícios públicos, como o Congresso, no canto inferior, à direita, e a Prefeitura, na esquina, à esquerda, do novo bulevar.

Além desse projeto, a praça foi tema de duas fotografias. A primeira delas expõe uma vista tomada a partir da Casa de Governo em direção ao Cabildo e mostra algumas das reformas propostas por Alvear já concretizadas, como sua arborização com palmeiras oriundas

${ }^{9}$ Cf. GORELIK, Adrián. La grilla y el parque. Espacio público y cultural urbana en Buenos Aires, 18871936. Buenos Aires: Universidad Nacional de Quilmes, 2010, p. 13 
do Rio de Janeiro (Figura 2). A segunda retrata a demolição da Recova Vieja (Figura 3), em 1883, obra vista como importante marco simbólico da derrubada da antiga cidade de feições ainda coloniais e da construção da metrópole moderna. Contudo, apenas três entre as 29 fotografias que compõem o álbum trazem o "durante" de uma obra de melhoria, e não o "depois", que caracterizou a maior parte das imagens, retratando projetos acabados. No caso específico da fotografia da demolição da Recova, há ainda outra exceção em relação ao conjunto das imagens do álbum: ela foi produzida antes da reeleição do prefeito, o que leva a crer que Halitzky fotografou o evento mesmo sem ter sido contratado para a tarefa, ou que ele produziu a fotografia como uma encomenda avulsa, num momento em que o álbum ainda não estava sendo preparado como tal.

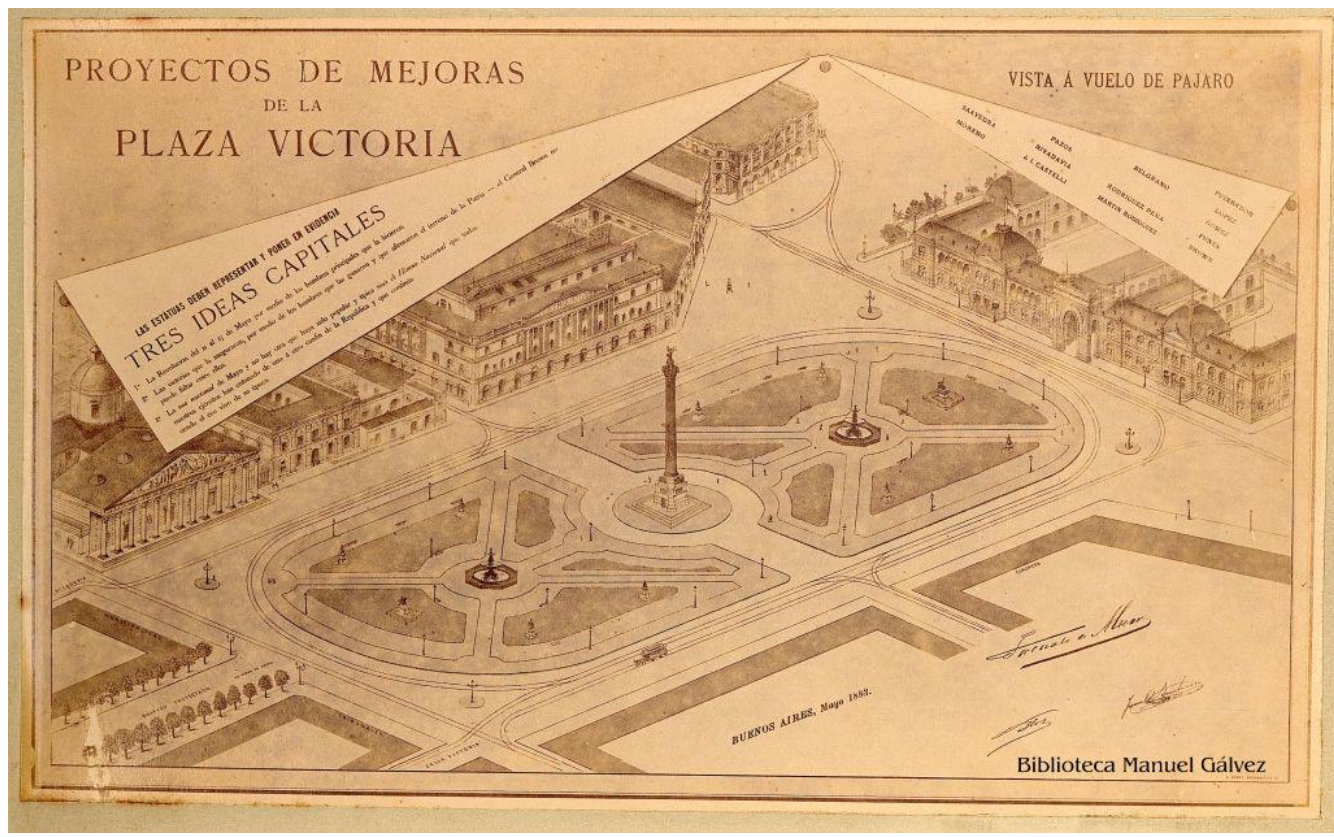

Figura 1: Projeto de Torcuato de Alvear para reforma da Plaza de la Victoria, 1883, fotografia de Emilio Halitzky.

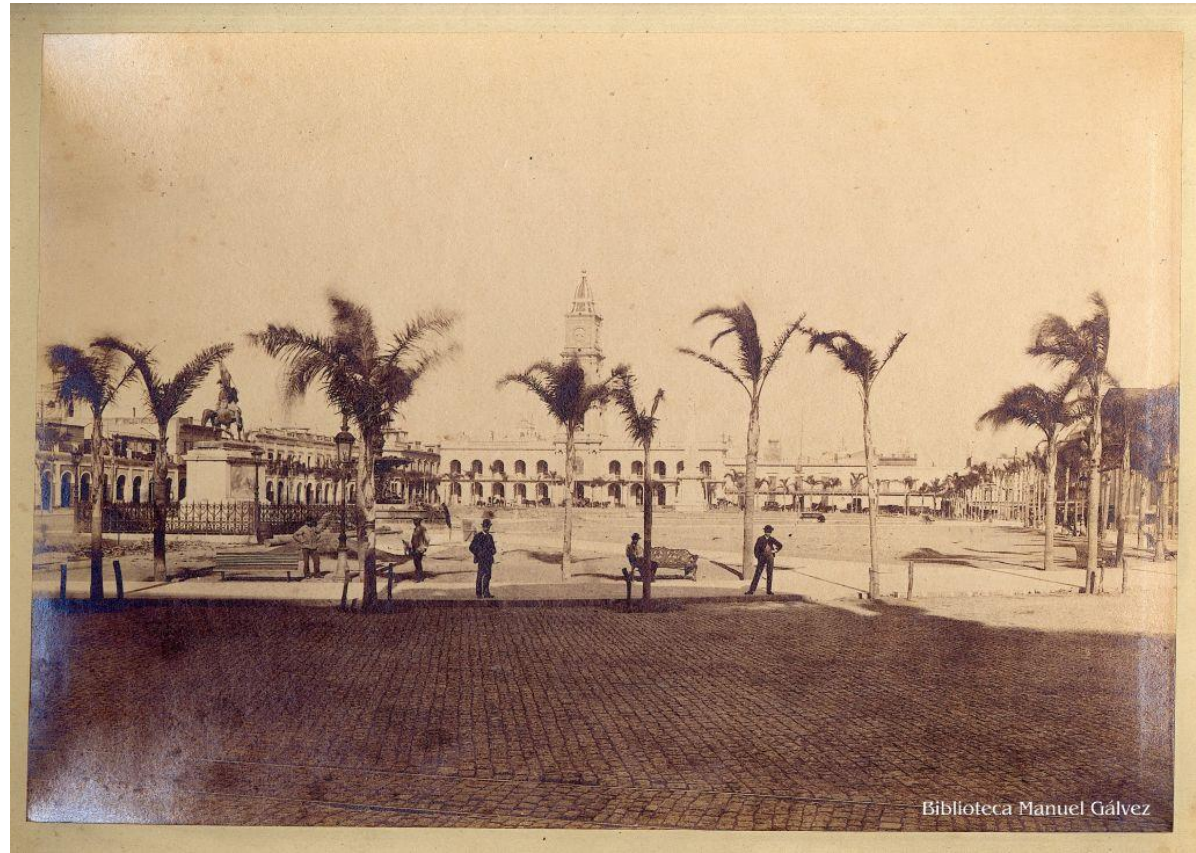

Figura 2: Plaza de Mayo, 1885, fotografia de Emilio Halitzky. 


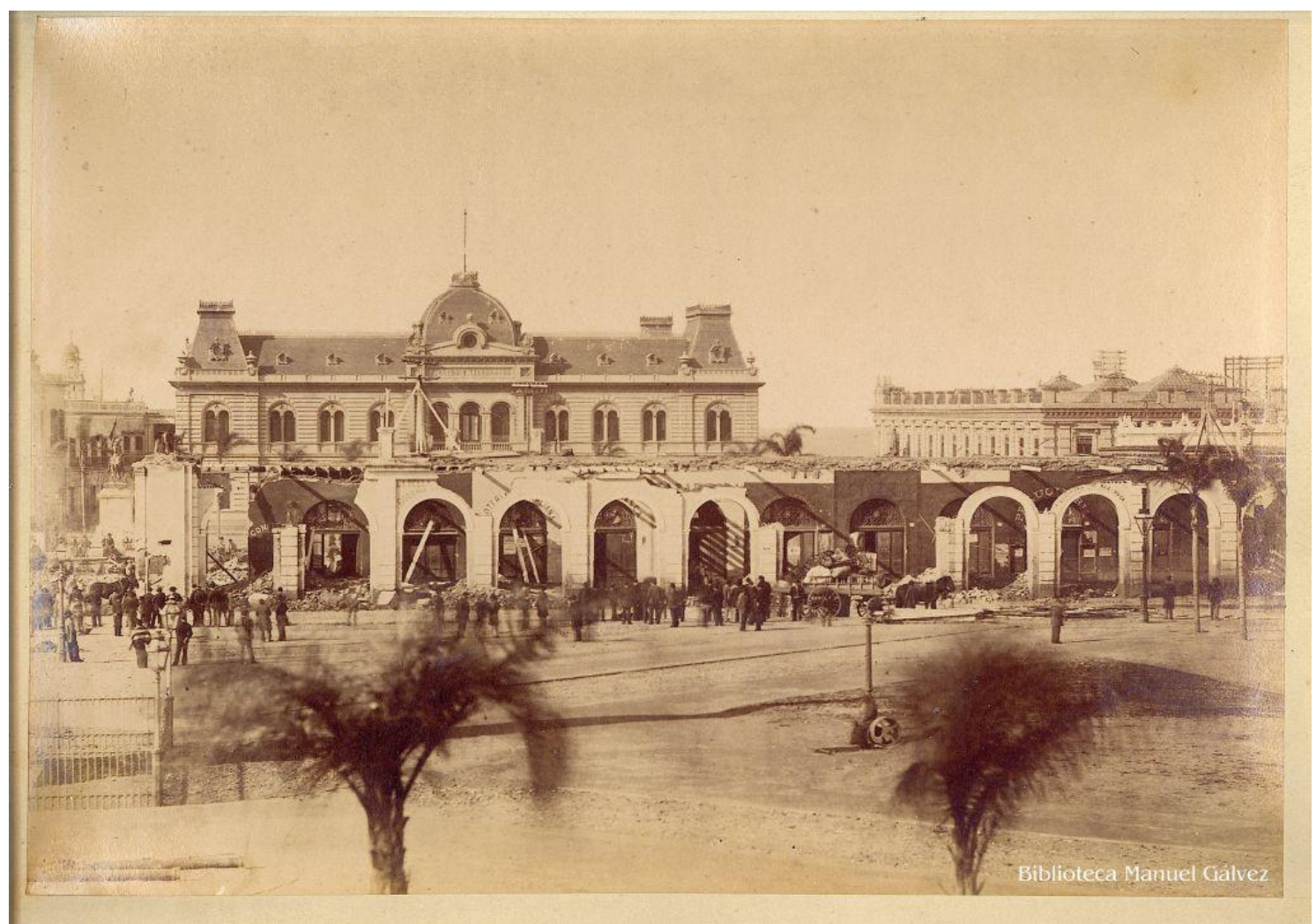

Figura 3: Obra de demolição da Recova Vieja, 1883, fotografia de Emilio Halitzky.

As tomadas feitas por Emilio Halitzky para composição do álbum têm em comum a característica de mostrar, além do caráter ordenado e sistemático da modernização urbana, uma cidade praticamente deserta, cujas imagens raramente incluíram componentes móveis, como pessoas e veículos. À exceção da fotografia que registra a demolição da Recova Vieja que retratou o que parecem ser tanto operários quanto curiosos que observavam a obra, posicionados a distância, de costas, e, provavelmente, ignorando o fato de que estavam sendo captados numa fotografia -, as pessoas retratadas aparecem geralmente posando para o fotógrafo. As paisagens urbanas desabitadas, arborizadas e aparentemente muito silenciosas chegam a contrastar com a noção de que, a partir da década de 1880, Buenos Aires se tornava uma cidade cada vez mais populosa e movimentada - noção presente em tantas outras representações, visuais e verbais, desse mesmo período.

Ao observar diversas fotografias que retrataram Buenos Aires entre as três últimas décadas do século $\mathrm{XIX}$ e a primeira década do $\mathrm{XX}$, Jorge Francisco Liernur ${ }^{10}$ identificou que, mesmo em imagens que buscavam evidenciar a construção do projeto de cidade moderna e ordenada, havia traços da existência de uma cidade improvisada e efêmera, mais do que estas mesmas representações pretendiam apresentar. Levando em consideração o caráter provisório do tipo de material com os quais se erguiam diversas construções na cidade - desde moradias populares até teatros, estabelecimentos comerciais e industriais construídos com tábuas de madeira, chapas de zinco e outros materiais pré-fabricados, mostrando que tais edificações

10 LIERNUR, Jorge F. "La ciudad efímera". In: LIERNUR, Jorge F. SILVESTRI, Graciela. El umbral de la metrópolis: transformaciones técnicas y cultura en la modernización de Buenos Aires (1870-1930). Buenos Aires: Sudamericana, 1992. 
visavam menos à durabilidade do que à rapidez com que se erguiam -, Liernur observa, naquela Buenos Aires finissecular, certa feição de acampamento.

Tal "cidade efêmera" existia paralelamente e não correspondia plenamente às representações regressistas, que viam a Buenos Aires de então ainda como a grande aldeia hispânica, tampouco às progressistas, que avaliavam a cidade como uma grande metrópole moderna. Sinais de um tempo intermediário entre as duas representações, essas construções de caráter precário e transitório identificadas pelo autor entre os elementos periféricos de várias fotografias revelariam vestígios do caos e da fugacidade característica daquele período, rompendo com a noção de cidade coerente e sólida recorrente em suas representações.

É razoável pensar que ao longo da segunda metade do século passado [século XIX], e especialmente nas décadas que se seguiram a Caseros, um lugar de tão vertiginoso crescimento quanto Buenos Aires tivesse mais o aspecto de faroeste do que de monótono povoado colonial ou de luminosa metrópole europeia. Isto é, a Buenos Aires desses anos possivelmente era muito mais americana, mais modernamente americana - e, com isso, não formalizada e caótica - do que estamos habituados a imaginar. ${ }^{11}$ (Grifo do autor)

A cidade não formalizada e caótica a que se refere Liernur não se configurava como o tema central das fotografias, mas era justamente o desvio, a periferia, o acaso naquelas imagens. Talvez graças ao fato de que esses construtos provisórios não tenham sido o motivo central das representações, o próprio reconhecimento desse período de fugacidade como uma característica marcante daquela cidade latino-americana finissecular tenha se tornado igualmente fugidio. Desse modo, a Buenos Aires sólida e coerente veiculada pelas interpretações que a identificaram, seja como "grande aldeia", seja como "metrópole europeia", deixou marcas no imaginário do nosso presente que a "cidade efêmera" não foi capaz de perpetuar, pois ela "não deixou os vestígios de papel dos projetos nem os muros adornados que hoje nos impressionam", de modo que, "não teve a força necessária para marcar a nossa cidade do presente". ${ }^{12}$

Imagens como as apresentadas em Mejoras de la capital de la República Argentina... são importantes exemplos de representações que, em sua maioria, suprimiram os vestígios do transitório ou do caótico; e, nesse caso, de modo mais radical do que nas fotografias pertencentes ao Álbum de vistas, tipos y costumbres del Buenos Aires Antiguo, da Casa Witcomb - imagens particularmente analisadas por Liernur. O cuidado em retratar os motivos centrais, incluindo poucos elementos ou nenhum elemento periférico, sugeria aos futuros observadores a realização de um projeto moderno que parecia não possuir rivais.

O álbum sobre as melhorias de Buenos Aires sob a administração de Alvear continha, entretanto, duas imagens que mostram uma construção que possui o caráter efêmero ao qual Liernur se refere. Trata-se da instalação de um hospital provisório, construído com materiais pré-fabricados, para o tratamento de doenças contagiosas numa região que corresponde hoje

\footnotetext{
${ }^{11}$ Id., p. 178.

${ }^{12}$ Id., p. 178.
} 

ao bairro de Parque Patricios, no sul da cidade. Tal como a fotografia da demolição da Recova Vieja (Figura 3), a imagem do hospital provisório (Figura 4) registra uma obra em processo de execução; mas, diferentemente daquela, revela a prática de buscar soluções momentâneas, paralelamente às edificações sólidas e duradouras, como a do hospital Ramos Mejía (Figura 5).

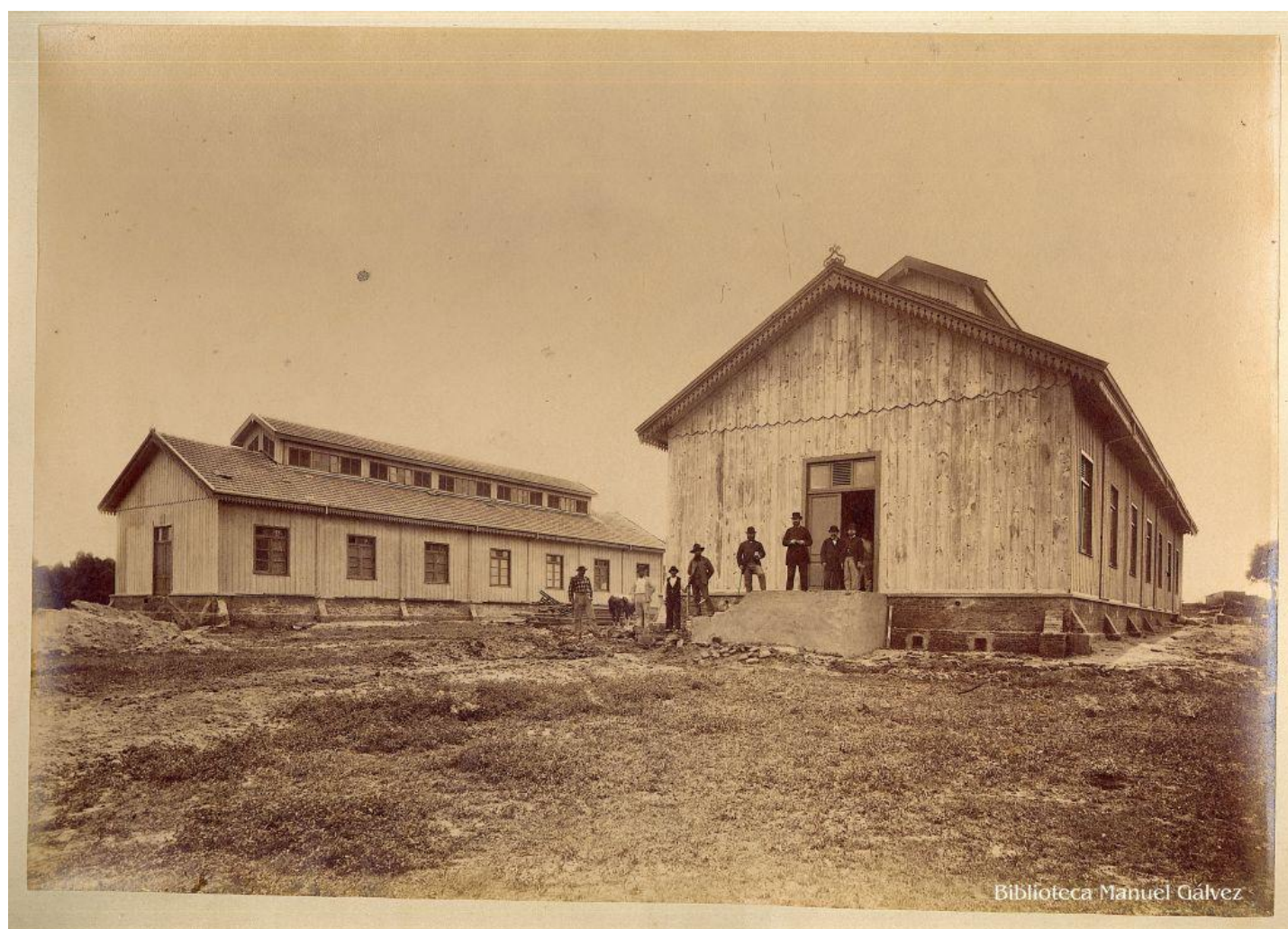

Figura 4: Obra de construção de hospital provisório na zona sul de Buenos Aires, 1885, fotografia de Emilio Halitzky.

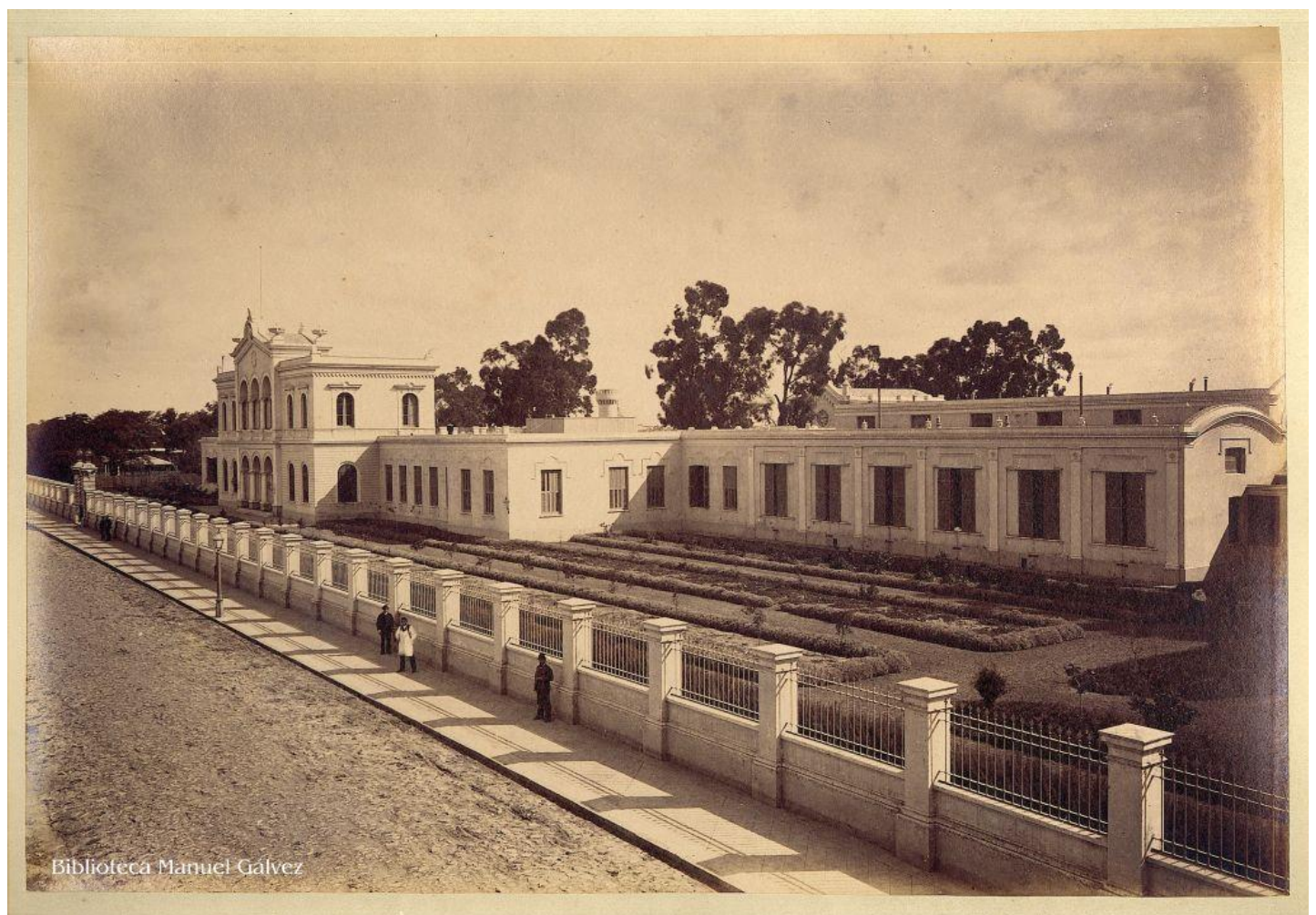

Figura 5: Hospital Ramos Mejía, 1885, fotografia de Emilio Halitzky. 
Se as mudanças rápidas que se processavam nas cidades em reforma podiam gerar alguma sensação de desconforto diante da destruição de marcos históricos e de referências espaciais tradicionais da cidade, provocando, com isso, instabilidade e estranhamento, o álbum de Halitzky não parece enfatizar a ideia de uma transformação urbana veloz e radical. A Buenos Aires construída ao longo do álbum não prioriza a apresentação da urbe moderna caracterizada pela aceleração das trocas comerciais, do crescimento populacional e de atividades produtivas; mas da urbe moderna identificada pelas áreas verdes, pelas ruas pavimentadas e pela preocupação com a saúde da população.

Nem mesmo a fotografia da demolição da Recova parece apelar para a noção de uma transformação rápida e dramática da paisagem urbana. Se a compararmos, por exemplo, com outra fotografia produzida sobre o mesmo acontecimento, pertencente ao Álbum de vistas, tipos y costumbres del Buenos Aires Antiguo, da Casa Witcomb, vemos que esta imagem (Figura 6) retrata o trabalho de operários no alto da construção; a Pirâmide de Mayo, cuja permanência na mesma praça estava ameaçada naquele momento; além de uma grande quantidade de entulho, localizado à direita, apresentando o local bastante desordenado devido à obra, elementos que foram inteiramente suprimidos da cena composta por Halitzky.

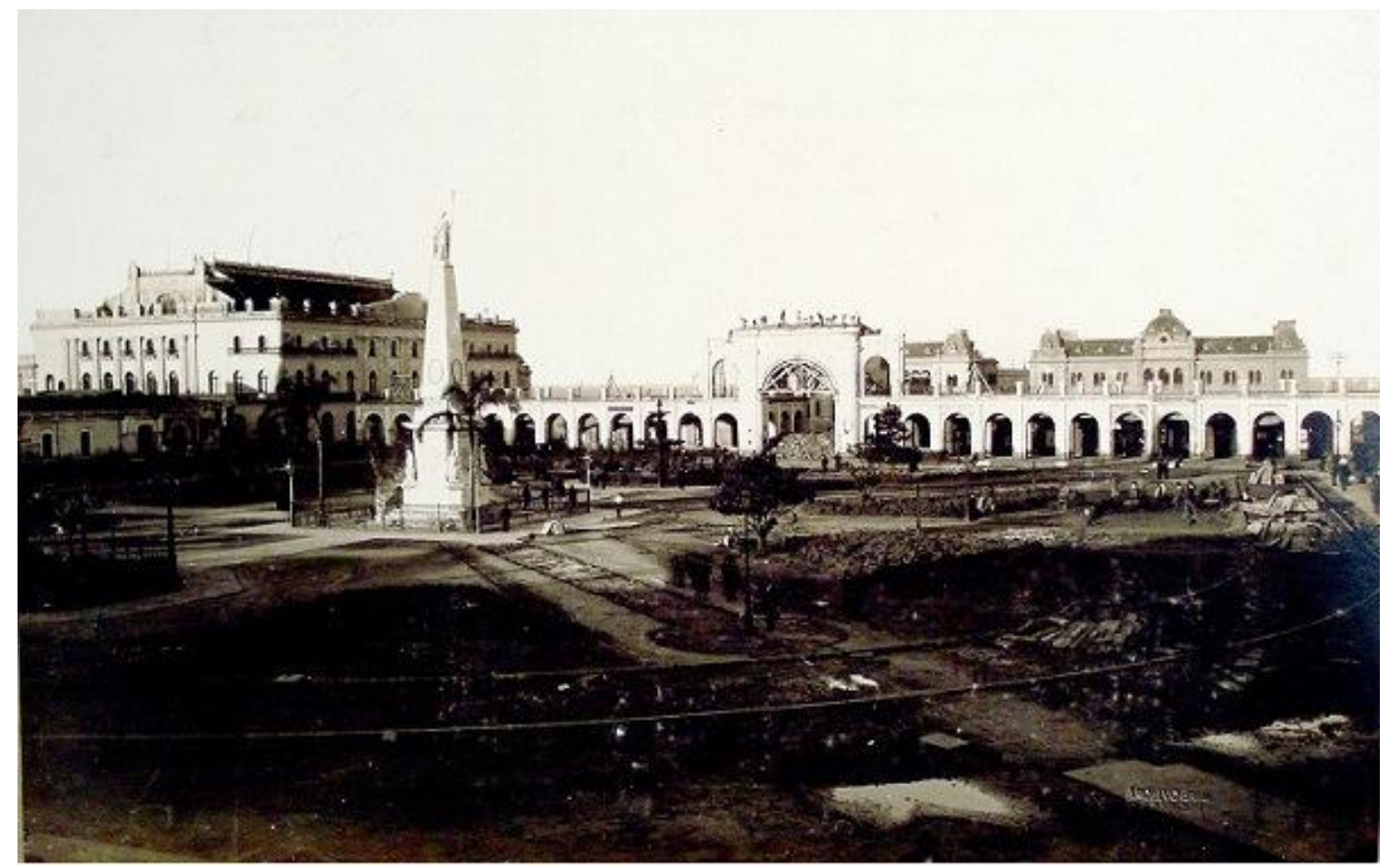

Figura 6: Obra de demolição da Recova Vieja, 1883, fotografia de Alejandro Witcomb.

Tais exclusões são relevantes para a análise da mensagem que o fotógrafo elaborou a partir da escolha de uma organização plástica específica. Sendo uma de suas primeiras tarefas selecionar o que estará dentro e o que permanecerá fora do espaço propriamente visual, o fotógrafo inclui no visor o que opta por mostrar, deixando de lado o que não Ihe interessa, por alguma razão, incluir na cena retratada. A respeito da importância do que chamou de o "forade-campo fotográfico", Philippe Dubois adverte que: 
O espaço off, não retido pelo recorte, ao mesmo tempo que ausente do campo da representação, nem por isso deixa de estar sempre marcado originalmente por sua relação de contiguidade com o espaço inscrito no quadro: sabe-se que esse ausente está presente, mas fora-de-campo, sabe-se que esteve ali no momento da tomada, mas ao lado. ${ }^{13}$ (Grifo do autor)

Ao se concentrar, sobretudo, em obras já concluídas, as imagens veiculadas em Mejoras de la capital de la República Argentina... minimizam a importância do que havia "antes" e "ao redor" dos espaços reformados. Com isso, em vez de destacar o momento da reforma como a derrubada de um passado que se pretendia superar, o que a maior parte dessas imagens faz é tornar notória a nova configuração urbana, em todo o seu esplendor, como se a história da cidade começasse apenas a partir daquele momento e daqueles projetos sólidos de modernidade formal e prospectiva. As imagens que retratam parques, passeios e ruas pavimentadas em vários pontos da cidade corroboram a apresentação dessa cidade moderna e ordenada, salubre e tranquila, repleta de áreas verdes que foram dispostas por Halitzky de modo a apagar, pelo menos dos registros fotográficos, não só as formas do crescimento urbano que escapavam a tais projetos, mas também dois elementos considerados tão tradicionais quanto detestáveis da cidade de Buenos Aires: o horizonte pampeano sem fim e o quadriculado de suas ruas, que repetia na paisagem urbana a mesma monotonia da sua paisagem natural.

Especialmente nas fotografias que retrataram os parques construídos ou reformados, a vegetação, as lagoas e grutas, os caminhos curvilíneos criados para os pedestres instituem na imagem a atmosfera pitoresca tão almejada, como fica evidente na fotografia do Paseo de la Recoleta (Figura 7). Em outras tomadas, como a que mostra a pavimentação da rua Callao (Figura 8), o Rio da Prata foi buscado como ponto de fuga, convertido ao mesmo tempo numa paisagem natural de fundo e num limite para a paisagem urbana, escapando da planície infinita e enfadonha do pampa. Já numa fotografia da Plaza Once de Septiembre, hoje Plaza Miserere, (Figura 9), plana e com árvores ainda muito baixas para que pudessem imprimir verticalidade à cena, a composição valorizou as vias sinuosas, formando curvas que se aproximavam ou se afastavam da via enquadrada no centro da imagem. Ao mesmo tempo que captou o horizonte plano, que não chegava a ser desnivelado pelos poucos prédios que superavam dois andares de altura ou pelas chaminés, captadas ao fundo, o ponto de vista usado para a tomada enfatizou as alamedas curvilíneas e os gramados em formatos irregulares, em primeiro plano, dispondo essas formas construídas a partir da reforma urbana como elementos centrais da cena.

${ }^{13}$ DUBOIS, Philippe. O ato fotográfico e outros ensaios. Campinas: Papirus, 1993. p. 179. 


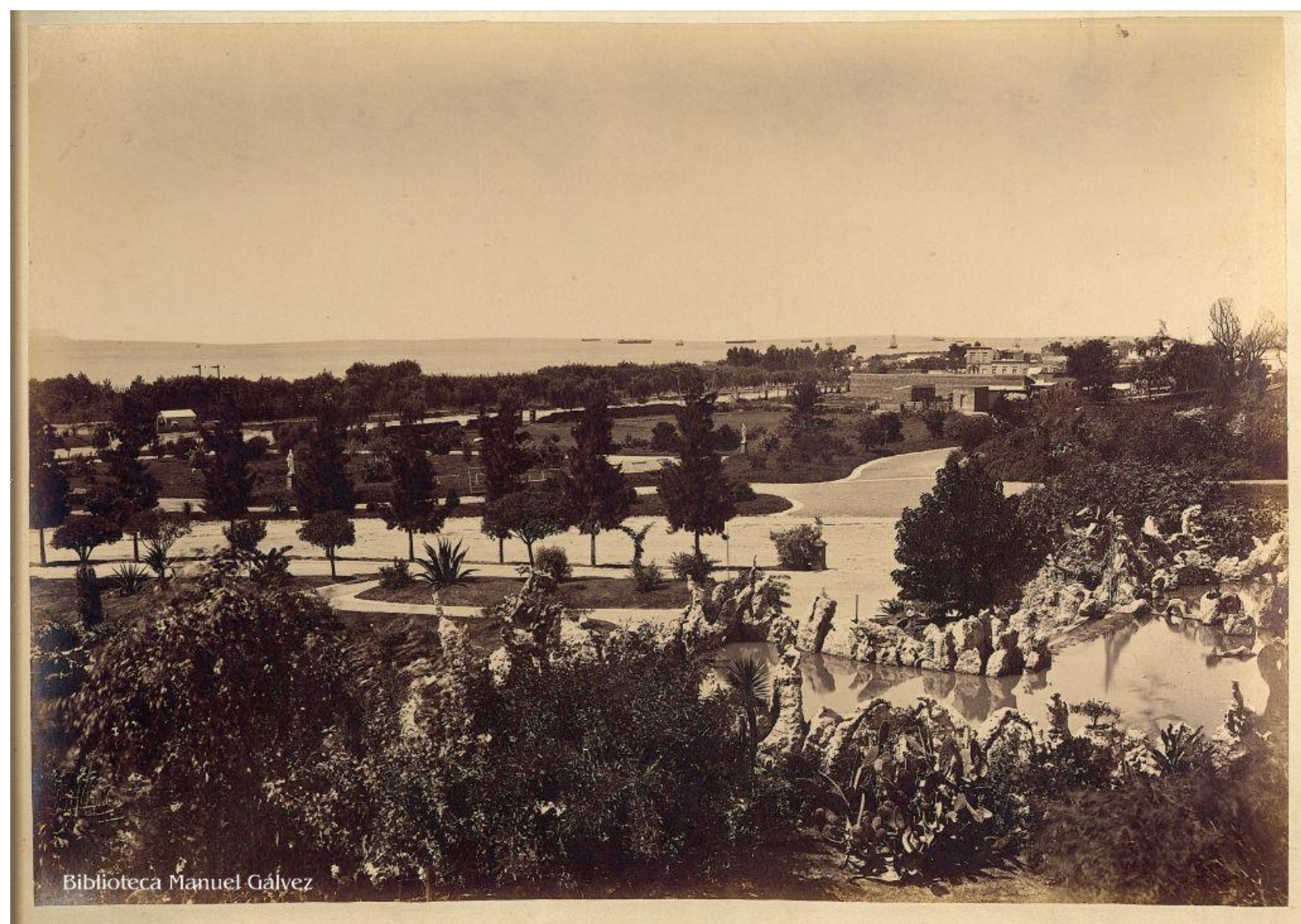

Figura 7: Paseo de la Recoleta, 1885, fotografia de Emilio Halitzky.

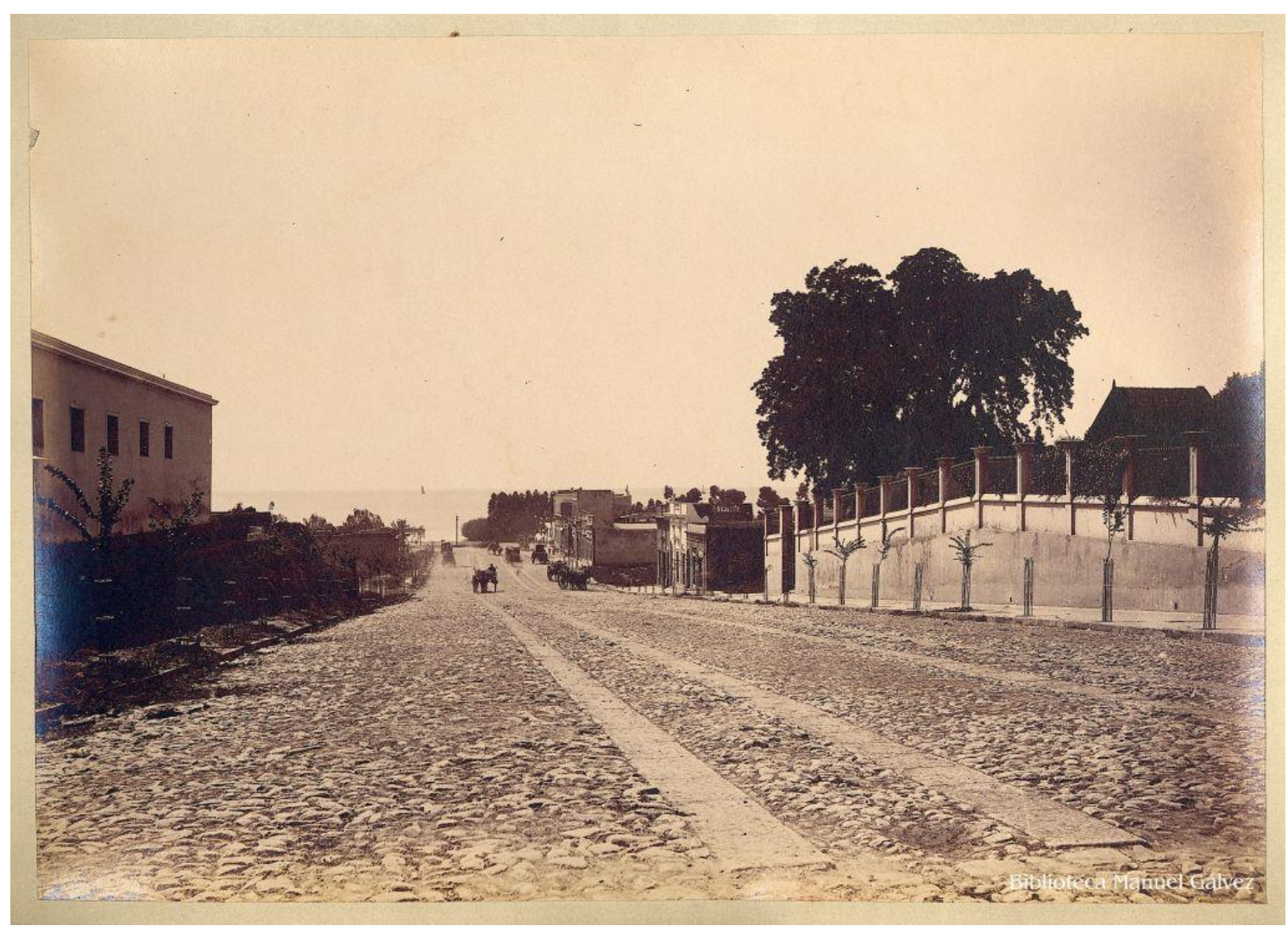

Figura 8: Vista da rua Callao, 1885, fotografia de Emilio Halitzky. 


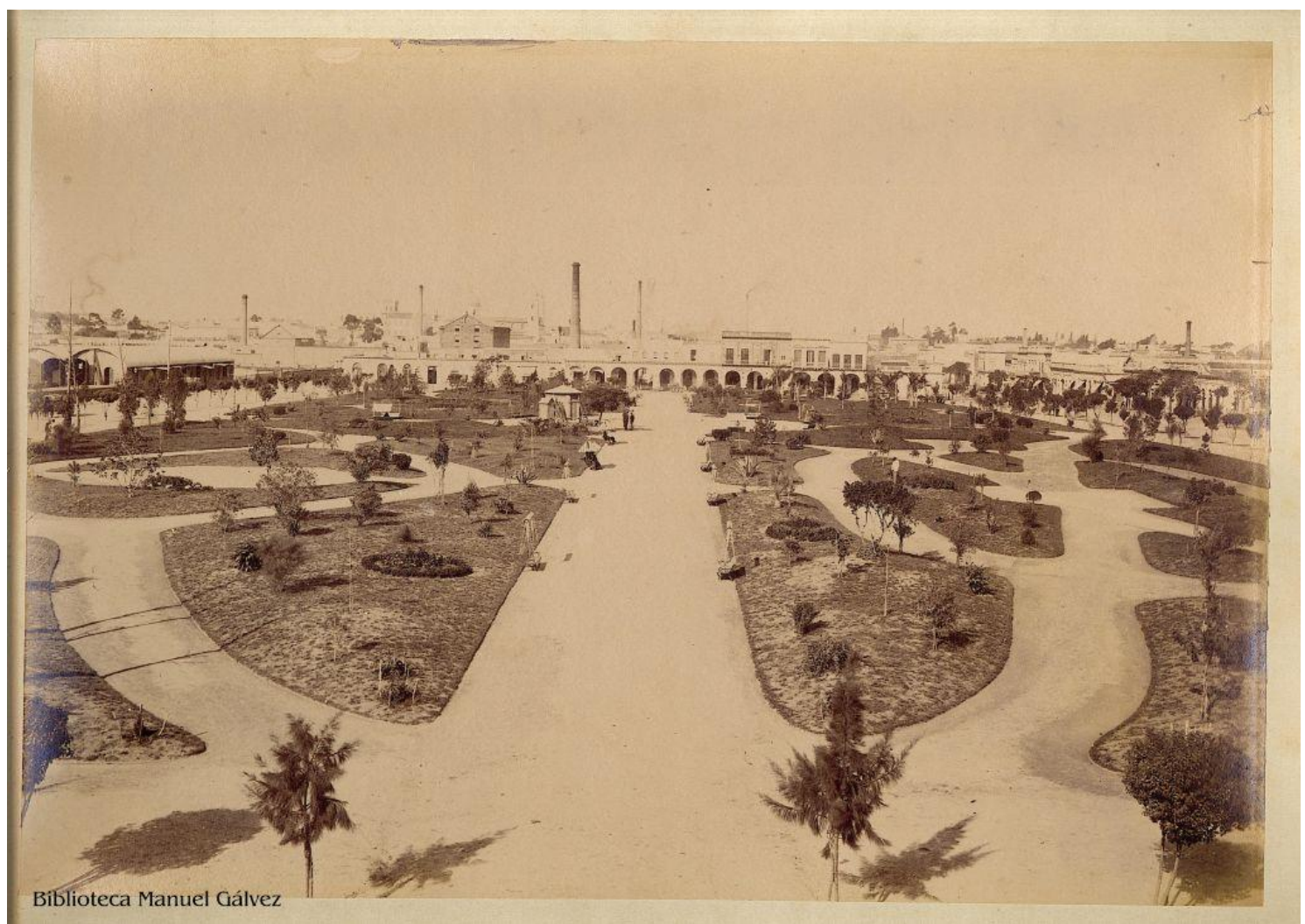

Figura 9: Plaza Once de Septiembre, 1885, fotografia de Emilio Halitzky.

É provável que a opção por retratar tanto as ruas quanto os parques praticamente vazios não tenha sido uma exigência do contratante do álbum, e sim uma decisão do próprio fotógrafo, que assim preferiu por razões técnicas ou estéticas e optou por dias e horários de menor movimento para realizar suas tomadas. De qualquer modo, a partir dessa opção, Halitzky produziu imagens de paisagens urbanas e edificações "limpas", evitando a inclusão de elementos que pudessem disputar com as próprias reformas de Alvear o papel de protagonistas das cenas. O que se sobressai é a imagem de uma cidade salubre, cujo registro da construção ou reforma de cemitérios, asilos e hospitais pudesse corroborar, além de uma cidade tranquila, ordenada, com ruas calçadas e terraplanadas, de modo a facilitar o tráfego de veículos e o acesso às margens do Rio da Prata e com os traços de pitoresquismo da vegetação e das curvas nas vias construídas no interior dos parques.

\section{Considerações finais}

As reformas urbanas empreendidas em Buenos Aires sob a direção de Torcuato de Alvear visavam à modernização ampla da estrutura urbana, prevendo tanto o embelezamento quanto a melhoria das condições sanitárias na cidade. As iniciativas envolviam medidas como o alargamento e a pavimentação de diversas ruas, a ampliação das redes de água potável e esgoto, bem como de iluminação e transporte, a normatização das condições de higiene das moradias coletivas e da distribuição de alimentos, a reforma e a construção de praças, assim como de hospitais e asilos. Contudo, os empreendimentos municipais não previam apenas a 
transformação material do espaço urbano, mas envolveram ainda a construção simbólica de uma imagem moderna para a cidade por meio de representações visuais da nova urbe que surgia. A produção, em 1885, do álbum Mejoras de la capital de la República Argentina... corrobora a noção, explorada no início do presente artigo, de que os progressos de Buenos Aires a partir de 1880 não eram apenas passíveis de serem vistos, mas que a produção de uma "imagem de progresso" era um dos objetivos daquelas transformações.

A contratação de fotógrafos com a finalidade de documentar o desenvolvimento de reformas foi uma prática muito frequente desde a segunda metade do século XIX. Ao retratar as reformas urbanas, a fotografia atendia à demanda de que as intervenções fossem documentadas a partir de um meio capaz de promover seu registro e sua divulgação da maneira considerada, então, a mais irrefutável de que se dispunha. Além disso, eternizar tal transformação através da fotografia servia ao propósito de inscrever aquele tempo novo na história da cidade, evidenciando este tempo novo como o nascimento da cidade moderna.

A fotografia efetua uma espécie de suspensão do tempo, por meio de um gesto que recorta não apenas de determinada porção do espaço observado, como também de um tempo que segue transcorrendo depois da realização da tomada que eternizou aquele instante. Tendo em vista essa característica própria à fotografia, é interessante perceber que, ao observar uma rua pavimentada ou uma praça reformada captada por Emilio Halitzky, vemos imagens que eternizaram determinados espaços como se estes fossem eternos. Ao deixar de registrar junto ao tema central praticamente qualquer tipo de elemento periférico, o fotógrafo enfatizava a nova paisagem urbana, criando por meio dela novos vínculos simbólicos entre a cidade e os citadinos. Vínculos estes que geraram, mais ou menos conscientemente, certo apagamento da urbe moderna como não formalizada e caótica - a "cidade efêmera" a que se refere Liernur - e corroboraram a criação da urbe moderna como algo para "ser visto", para utilizar os termos de Ezequiel Martínez Estrada que vimos no início deste artigo. Com poucas exceções, ao fotografar obras finalizadas, em cenas que evitavam que o observador identificasse elementos aos quais pudesse associar o que havia existido ali anteriormente ou que existia ao redor do tema central, o álbum das melhorias de Buenos Aires produziu a imagem de uma cidade salubre e aprazível, livre da tensão e do estranhamento que as próprias transformações poderiam provocar.

Viviane da Silva Araujo: Doutora em História pelo Programa de Pós-Graduação em História Social da Cultura da PUC-Rio, atualmente é professora adjunta da UNILA Universidade Federal da Integração Latino-Americana, integrando o Instituto Latino-Americano de Arte, Cultura e História. 